\title{
Open Access, library and publisher competition, and the evolution of general commerce
}

\author{
Andrew Odlyzko \\ School of Mathematics \\ University of Minnesota \\ Minneapolis, MN 55455, USA \\ odlyzko@umn.edu \\ http://www.dtc.umn.edu/ odlyzko \\ Preliminary version, February 4, 2013
}

\begin{abstract}
Discussions of the economics of scholarly communication are usually devoted to Open Access, rising journal prices, publisher profits, and boycotts. That ignores what seems a much more important development in this market. Publishers, through the oft-reviled "Big Deal" packages, are providing much greater and more egalitarian access to the journal literature, an approximation to true Open Access. In the process they are also marginalizing libraries, and obtaining a greater share of the resources going into scholarly communication. This is enabling a continuation of publisher profits as well as of what for decades has been called "unsustainable journal price escalation." It is also inhibiting the spread of Open Access, and potentially leading to an oligopoly of publishers controlling distribution through large-scale licensing.

The "Big Deal" practices are worth studying for several general reasons. The degree to which publishers succeed in diminishing the role of libraries may be an indicator of the degree and speed at which universities transform themselves. More importantly, these "Big Deals" appear to point the way to the future of the whole economy, where progress is characterized by declining privacy, increasing price discrimination, increasing opaqueness in pricing, increasing reliance on low-paid or upaid work of others for profits, and business models that depend on customer inertia.
\end{abstract}

\section{Introduction}

Concerns about libraries not being able to afford rapidly escalating journal costs go back many decades. Over the last 15 to 20 years, they have intensified. This was partially because the cost pressures have become more burdensome. Perhaps even more important has been the arrival of the Internet, as well as of computerized typesetting and other modern electronic tools. These have offered the possibility of much less expensive methods of scholarly publishing. As one result, there has been an increased push for various forms of Open Access (which is also being advocated for other reasons, in order to make information more widely available). There have also been calls for scholars to stop collaborating with the expensive commercial publishers, by refusing to submit their papers to them, as well 
as to referee submissions or edit journals. The most recent prominent call of this nature was initiated by Tim Gowers in early 2012, and as of this writing has attracted over 13,000 signers [19].

Protesters, such as those who endorse the boycott [19], tend to cite the high profits of commercial publishers, most commonly of Elsevier, the largest one, as injurious to scholarly communication, and unjust, being based on donated labor of academics. They also often complain about the "Big Deals" that large publishers, again with Elsevier in the forefront, force libraries into, cf. [4],11]. In these contracts, which are universally shrouded in secrecy (although an interesting project is revealing some of the details [12]), libraries are forced to accept multi-year commitments with steady price escalation and little flexibility in selecting what journals they get. This has all the obvious disadvantages for libraries and the academic community. However, such discussions almost universally ignore the positive effects of the "Big Deals," as well as the degree to which those positive effects are key to the main action in scholarly publishing, namely the competition between libraries and publishers.

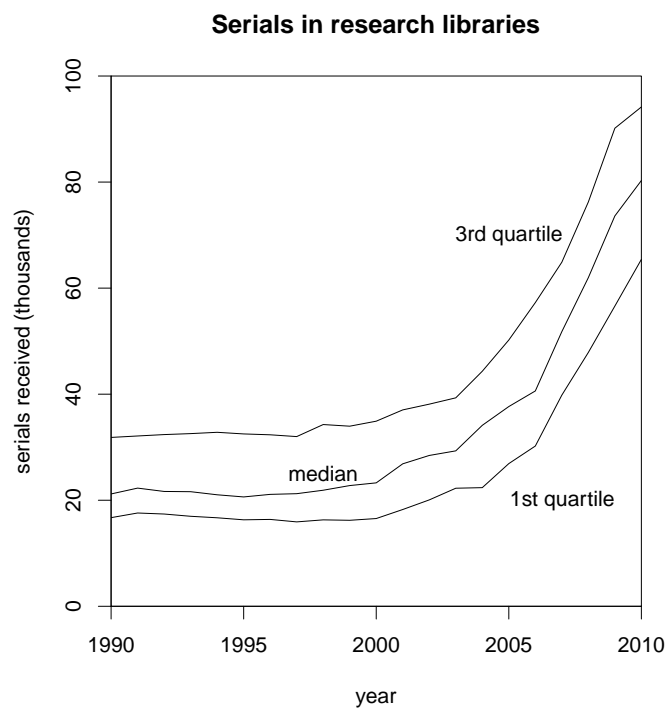

Fig. 1. Number of serials available in research libraries from 1990 to 2010. Shows the median as well as the first and third quartiles of the number of serials received by academic members of ARL.

The main contribution of this paper is an investigation of the effects of the reviled "Big Deals" on access to scholarly journals. In spite of their low reputation, over the last decade they have produced a remarkable increase in availability of serials. This is shown in Fig. 1 and is discussed in more detail in Section 4. The data for the analysis is taken from the careful and detailed statistics for the 115 academic members of the Association of Research Libraries (ARL) [9]. Those members include almost all large university libraries in the U.S. and Canada. (For more about ARL, its statistics, and the selection of data, see Section 5.) 
The median of the number of serials received by ARL members almost quadrupled during the period under investigation, going from 21,187 in the 1989-1990 academic year to 80,292 in the 2009-2010 one. Practically the entire increase took place during the last half a dozen years, without any big changes in funding patterns, and appears to be due primarily to "Big Deals."

Members of ARL are all large libraries, but with substantial variation. In the 2009-2010 academic year their budgets (as defined by ARL) ranged from $\$ 8.3$ to $\$ 111.6$ million, with a median of $\$ 22.8$ million. Thus improved access to journals for just these institutions still leaves out in the cold the general public as well as students and researchers at many hundreds of other higher education institutions in North America, as well as potential readers in other countries. (It should be noted, though, that many of those institutions do appear to be benefiting from "Big Deals" and other arrangements, it's just that this study is limited to ARL members by the nature of the data that is was available .) It also ignores wider issues of access to other types of information, cf. [49]. Still, these 115 institutions do contain a very substantial fraction of both authors of scholarly journal papers as well as of readers. Thus it is of interest to see what the recent trends have meant for them, especially since there are analogies and implications for the wider economy.

Fig. 1 demonstrates not only that the average number of serials available in ARL libraries has grown, but that gaps between the large and small libraries have decreased. This is shown in more detail in Section 4, especially in Fig. 2. Section 5 proves that this occurred without any dramatic changes in either relative or absolute spending on serials. This socially positive development is the outcome of the growth in price discrimination, the selling of the same product or service at prices varying depending on customer. As an example, in 2007 unlimited access to the entire collection of journals published by Elsevier cost the University of Michigan $\$ 1,961,938.75$, while the University of Montana paid $\$ 442,224.78$. Such practices are increasingly common, although usually carefully hidden from view. (Uncovering this degree of differential pricing required considerable effort by Ted Bergstrom and his collaborators, including fighting a lawsuit from Elsevier [12].) Hence the spread of "Big Deals" provides interesting perspectives on the development of the modern economy, a topic pursued in the final sections of this paper. Before considering that wide subject, let us return to the scholarly journal crisis.

Can commercial publishers continue to prosper? Financial analysts are divided. A team from Exane Paribas in Paris declared (as cited in [67]) that the boycott initiated by Gowers [19] was effectively a tempest in a teacup, and that sales of Elsevier shares by investors foolish enough to be scared offered a "trading opportunity." On the other hand, Claudio Aspesi and his colleagues at Bernstein Research in London have been bearish on the commercial STM (science, technology, and medicine) publishing sector for several years (cf. [5,6] and other reports) and decided the recent events were foretelling serious trouble [7].

The bearish views on Elsevier are based largely on the estimate that the "Big Deals" are becoming unaffordably expensive and will soon start breaking down. That might happen. However, the complaints about unaffordable journals go back many decades, yet they somehow have been afforded. To understand how this was possible, one needs to take a larger view of the economics of scholarly communication. The high profits earned by 
commercial publishers, as well as by many non-profit professional societies, are one of the lesser inefficiencies in that system. Those profits are just a fraction of the actual, and now unnecessary, real costs of the current scholarly journals. And those real publishing costs are much smaller than the (now) unnecessary real costs of the library system. Publishers have managed to continue with their "unaffordable" journal price increases by squeezing some of that inefficiency out of the libraries. And there is a lot more to be squeezed.

Discussions of the economics of scholarly publication almost uniformly ignore the dominant economic factor in that area, namely that most of the cost is inside libraries ${ }^{1}$, and that technology is making feasible and desirable the dramatic downsizing of traditional functions not just of publishers, but also of libraries [56,62]. (Those costs, in turn, are dwarfed by the costs to authors, editors, and referees, cf. Section 2, but those costs do not involve any money transfers and are not accounted for.) As a prime example, while librarians increasingly take on new roles, handling the huge volumes of books and bound serials is still a large part of the cost of library systems. Yet, at a rough estimate, 90\% of the books and $99 \%$ of the journals in a typical large academic library can, should, and will be sent to inexpensive off-site warehouses, with usage shifting to electronic copies. That will free up space and eliminate many of the jobs in the system.

The key role of high internal library costs in academic information systems is probably ignored because of a general reluctance to face unpleasant facts ${ }^{2}$. Libraries are central to the image of modern universities, the repositories of knowledge and wisdom. They are unifying institutions serving everybody on campus and often in the community at large. Their buildings are usually centrally located and among the most imposing around, and they are staffed by the helpful librarians, perhaps the best-loved group on campus. The notion of laying off those friendly librarian colleagues and closing down library facilities in order to sustain the profits of Elsevier is repugnant. But that is what we are facing. Furthermore, sending physical collections to inexpensive off-site warehouses, closing down physical library facilities, and limiting hours of operation of remaining ones, all of which has been taking place to only a limited extent so far, is not only inevitable, but desirable. Online access is more effective and is bound to dominate to an increasing extent. Such a transformation has already taken place 5 to an even greater extent in corporations, which have largely eliminated their libraries, but do pay for access to commercial databases, including those that contain scholarly materials.

ARL statistics, summarized in Section 5, show that while library budgets have grown much faster than general inflation, they have shrunk compared to university budgets. At the same time, the fraction of library costs that are devoted to purchases of books, journals, and databases has grown over the last two decades from about a quarter to about a third (if we consider the full costs of library systems). This indicates that libraries are becoming less important to universities, while publishers have roughly maintained their position by wresting more of the resources from the libraries. (There has also been growth in spending on other scholarly communication services outside the library/publisher area that are not captured in the ARL statistics.)

Among recent moves towards mandated open access in Britain, the Finch report and the RCUK Open Access policy have been criticized by many Open Access advocates for 
tilting towards publishers through an embrace of Gold Open Access (in which publishers are paid to make the articles in their journals publicly available). This is seen as potentially imposing crippling additional costs on researchers. However, although this was not mentioned explicitly in those reports, a very obvious move might be to recover those extra costs not from research funds, but from library budgets, and force cutbacks in traditional library functions. Thus while Aspesi et al. [8] have seen these recommendations as a threat to publishers, it may actually mean another victory in their competition with libraries.

Open Access is not the same as low-cost publishing. The two can be treated as orthogonal aspects of scholarly communication. However, the low costs made possibly by modern technology make a break with traditional high-cost subscription publishing models far more feasible. Andy Grove, the famous former CEO of Intel, argued that a 10-fold change in cost or capability of a technology requires fundamental rethinking of the basic business model. Electronics does offer the possibility of a 10-fold decrease of basic journal publishing costs. As one example, it is argued later in this paper that just the money that the ARL libraries alone spend on acquisition of serials would in principle suffice to fund an adequate Open Access publication support for all the scholarly journals in the world.

When I first embarked on studies of electronic publishing almost two decades ago, I concluded that Open Access was not just desirable, but also inevitable. It has manifold advantages for society as a whole and for scholars. However, the inertia of librarians and scholars has kept them from taking advantage of the opportunities offered by modern technologies. On the other hand, publishers have moved faster, and it now appears that subscription journals may survive for a long time, together with their associated unnecessarily high costs and unnecessarily high profits.

The evolution of scholarly publishing, including the changing roles of libraries and publishers, is of interest as a bellwether of change in academia in general. Two decades ago, the arrival of the Internet and other electronic technologies led to prophesies that universities were doomed [55]. Instead, as was easy to predict [61], they blossomed. (See Section 6 for some statistics.) Today a new wave of "disruptive innovation" is threatening the traditional academic model, with a proliferation of for-profit educational institutions as well as free massive online courses being cited as just the start of massive changes. Chances are that, as was argued in [61], there will be far less of a collapse than is promised (or threatened), and that the new techniques will be more of an addition than a replacement for traditional approaches. Education, just like medicine, is a growth business in a world that depends increasingly on training and expert knowledge. Hence this sector as a whole is not likely to shrink. However, change is likely. In particular, some of the trends in research that doomed old-style industrial research labs [57] are now showing up in universities. A natural development might lead to the abolition of traditional departments, for example. It will be interesting, therefore, to see the degree to which universities are willing, or are forced, to outsource their library functions to Google and publishers,. That might that serve as an indication of how likely more disruptive moves are to occur in academia.

More generally, the evolution of scholarly publishing provides interesting insights into the evolution of commerce in general. The availability of the comprehensive and reliable ARL statistics enables us to obtain quantitative measures of some phenomena that are 
usually hidden from view. One of the most important and interesting of these phenomena is the growth in price discrimination, as in the University of Michigan paying $\$ 2$ million for something that the University of Montana obtains for $\$ 440$ thousand. As was easy to predict a long time ago, differential pricing is the driver behind the systematic destruction of privacy. This is finally beginning to be slowly reflected in press coverage, cf. [15 25]. For the most part, though, it is studiously avoided, both in scholarly venues (such as the call for papers in the conference [29]) and in most newspaper articles, which cite arguments that data sharing rules should not be so tough as to "hinder or undermine the ability of companies to innovate" without explaining what kind of innovation is meant [76]. The reason this topic is so studiously avoided is likely because it is even less pleasant to think about than downsizing libraries in order to preserve Elsevier's profits. The logic of growing price discrimination leads to visions of a "dystopian future" [42], where many of the basic assumptions about the economy no longer apply. Scholarly publishing provides useful insights into why differential pricing is spreading, why it is spreading so slowly and surreptitiously, and why its spread is hard to resist.

Scholarly publishing also illustrates some other developments in the modern economy. The ability of consumers to find information and hunt for the best deals is justly celebrated [14,24], and has done much to improve the efficiency of the economy. But this development is accompanied by countervailing tendencies, such as greater opaquenes in other areas of the economy, as was evidenced by all the "toxic" financial instruments that facilitated the bubble that led to the crash of 2008. In journal pricing, we also observe greater opacity, with list prices being essentially meaningless, and real prices hidden behind non-disclosure clauses in sales contracts.

Some of the phenomena that scholars object to, such as publishers making profits out of the unpaid labor of authors, editors, and referees, are of ancient standing, and are now being replicated far more widely elsewhere in the economy. Many of the most successful tech companies of the modern era, such as Facebook and Google, derive their value from the unpaid labor of their users. Thus what is claimed to have been a possibly passing anomaly in scholarly publishing is actually becoming a central feature of the modern economy.

The core of this paper is Section 4, which explores the effect of "Big Deals" on access to scholarly information among ARL members. First, though, a general overview of scholarly journal cost structure and of the perils of technological and market prognostication is presented in Section 2. Then there is discussion of the value of quantity and quality in Section 3, since many scholars dismiss concerns about publishing by claiming that all that is needed is a tightening of standards in order to eliminate any crisis. Then comes Section 4 , as mentioned above. It is followed by Section 5, which describes the data sources that are used, and their limitations. Section 6 has a deeper look into the budgets and relative roles of universities, publishers, and libraries. Section 7 summarizes the arguments that scholarly journal publishing can be carried on at a far lower cost than it is at present. Section 8 delves into the competition between libraries and publishers, and what their best courses of action for the future are. Section 9 is the first of several sections on the development of the entire economy and how it relates to what we see in scholarly publishing. There is discussion of growing opaqueness, of the development of a "Tom Sawyer" trends (as in 
Tom Sawyer getting boys in his neighborhood to pay him for the "privilege" of doing Tom's chores), and of growing price discrimination. Finally, Section 12 has the conclusions.

\section{Open Access, academic publishing, and academic inertia}

I first became seriously involved in investigating scholarly publishing two decades ago, and concluded that some form of Open Access as well as new, lower cost, publishing models were desirable and inevitable [56]. Although I still feel they are desirable, it now appears far more questionable whether they are inevitable, at least in the form envisaged. The posting of preprints, while still not universal, is spreading, and the arguments for it are even stronger than before. However, the high cost journals are still surviving, and may continue to do so.

This paper is not about Open Access. Rather, it is about what is actually happening in the rest of scholarly publishing, and why instead of pure Open Access, we might instead end up with something that might have a similar effect. In particular, we might have various institutions paying subscription fees to high-cost publishers to provide access to wide classes of readers (potentially entire nations). Thus practically nothing will be said about the extensive literature on Open Access, on Green versus Gold models, and the like. Just a few references to that area are Peter Suber's blog and [13,34,35,38,39,53,54,78,81]. There is rapid growth in Open Access, as shown by some of these papers, by the Directory of Open Access Journals maintained at Lund University, and by other sources. The question is, is it fast enough to prevent publishers from entrenching their high-cost journal model. Thus, for example, in mathematics, arXiv receives about 25,000 submissions per year, but that is still only about one quarter of all mathematics papers that Mathematical Reviews processes each year. The growth rate in arXiv submissions is around $15 \%$ per year, a rate that is far faster than the approximately $3 \%$ per year growth in the number of articles, and not dissimilar to other growth rates observed in other aspects of Open Access. However, that growth is not as fast as what can be seen in Fig. 1 over the last few years for increase in access to serials at ARL libraries.

While there is no space in this paper for a complete review of the scholarly literature, it will be handy to build the presentation and analysis around my own earlier analyses and predictions for this subject, which provide useful background information on some of these issues. The first paper [56] estimated that a typical article cost about $\$ 20,000$ in author's time and $\$ 4,000$ in time of reviewers, both costs that don't show up in any budgets, but do reflect the effor devoted to scholarly publications by unpaid experts. It also estimated publisher revenues per article of about $\$ 4,000$, and internal library costs of about twice that. It also estimated that $\$ 300-1,000$ per paper would suffice for very good quality in an online-only environment, and that costs of digitizing old materials would be low (see also [59]). All those estimates still appear reasonable, and even lower costs have actually been demonstrated, as is discussed in Section 7 . These estimates were then used to argue for a shift to new low-cost and Open Access journals.

While the conclusions and predictions of [56] did reflect a realization of how much of an obstacle the inertia of the academic system posed, the main failure of that paper was in underestimating that inertia. An explanation (even if not an adequate excuse) for this 
was that the paper was written at an industrial research lab, so with an inadequate appreciation of how slowly everything changes in universities. I forecast in that paper that the high-cost journal system would not change materially for a decade, but would likely collapse within two decades. Had I had my current experience as a professor and university administrator, I would likely have doubled both estimates. As has been noted many times, "scholarly behavior is profoundly conservative where communication is concerned and that, if anything, younger members of a discipline are even more conservative than their elders who are better established" [47]. The growth in novel forms of peer review has been extremely slow. Even the high energy theoretical physicists, the first field to embrace the predecessor of arXiv, and to submit virtually all their preprints there, continue to publish most of their papers in conventional journals. A particularly telling observation is that even Stevan Harnad, that indefatigable advocate for Open Access, has scaled back his effort in this area in frustration.

Subsequent studies of rates of diffusion of technologies found that while new forms of communication were often embraced rapidly by scholars [63], that was not the case with the basic journal publications, which were often deeply embedded into the sociology of their fields, and so on their own would likely take generations to evolve substantially. The only way to speed up the process was to have "forcing agents," who can compel change [60]. In this area I expected university administrators to take the lead. However, with a few exceptions, they have been slow to act or lead either from ignorance, or pusillanimity, or perhaps from a deeper understanding of how fast academia can move. As a result Open Access mandates have been coming primarily from funding agencies, and relatively slowly.

The high internal costs of libraries compared to the purchase cost of serials was an obviously important factor [56 62]. Further, consideration of the entire scholarly communication system, in which publishers and librarians were the intermediaries between scholar authors and scholar readers led to the prediction that there would be an intensifying conflict between these two groups, as old roles became obsolete or were shifting, and new roles were emerging. From the beginning it seemed likely that publishers would be more successful at it than librarians [62. The evidence of this paper supports that prediction. However, the field is in a state of ferment, and it is hard to tell how the competition will turn out in the end, given that Open Access mandates are increasing, and new inexpensive journals are proliferating.

\section{Quantity, quality, and value}

The basic assumption made in this paper is that more information is better. We do have a rising chorus of complaints about information overload. Furthermore, most researchers depend most of the time on a limited number of information sources. This is the basis for some of the concerns about the viability of the "Big Deals" (see, for example [6]). Research libraries might reduce their subscriptions to just a small core of journals, and rely on purchasing access to individual articles as needed. Just how much are all those extra journals worth? Why can't the libraries be more selective?

There are several answers to that. There is a continuation of the traditional growth in the volume of scholarly information, at about the traditional $3 \%$ per year rate that has 
prevailed for many decades. There is no sign this is going to stop. Furthermore, with the increased emphasis on interdisciplinary and multidisciplinary research, there is a need for access to all the research that is being produced.

Second, all the evidence we have is that libraries are not very good at selecting the best. And, of course, the scholarly community itself is not very good at deciding what is the best. The defects in the editorial and refereeing processes have been known for long, and are becoming ever more apparent. Scholars cannot rely on just a narrow slice of available information even if it is confined to what has received the highest grade of approval from the current system.

Another answer is that all those extra journals must be worth something. This is demonstrated by the behavior of scholars and libraries in the past. After all, the bottom quarter (in terms of serials received) of ARL members obtained fewer than 17,000 serials in the 1999-2000 academic year, before "Big Deals" became dominant, while the top quarter all procured over 34,000. Why did those richer libraries bother? If the extra 17,000 serials could be dispensed with, why didn't those institutions save the millions of dollars that each one spent annually on acquiring them?

Further, decisions about usage, acquisition, and retention of scholarly material are made at the margin. And most of the current physical collections are of marginal value. One can imagine that in negotiations, in response to librarians' pleas that the "Big Deals" are unaffordable, publishers point out that they would be easily affordable if librarians sent off much of their hard copy material to distant and inexpensive storage facilities, shut down some library facilities, curtailed operating hours, and so on. All these steps would lower the level of access to useful information, but so would abandoning the the "Big Deals." The real question is, which hurts more? In either case, resources are devoted to providing access to material that, for the most part, has little value individually, but substantial value in total, not least in the "option value" of being able to access it when desired.

And of course there is much more that can be said in favor of wider availability. The Open Access movement is based on the argument that we need far wider distribution of research results. I won't attempt to survey all the arguments that have been produced, except to say that they are overwhelmingly persuasive, and are becoming ever more valid as scholarly literature grows and the need for and opportunities in interdisciplinary work increase.

Bradford's law from information sciences was formulated to provide a quantitative estimate of diminishing returns from search in journals. This "law" (which is an empirical observation, akin to various other "laws," such as those of Pareto and Zipf), together with other evidence from a variety of fields, suggests a more general rule [65] that as a very rough guide, information, whether in a library, or on a hard disk, or measured in transmission capacity, should be valued on a logarithmic scale. Thus if a collection of 10,000 serials is valued at 4, one that is 10 times as large, with 100,000 serials, might be worth 5 . That is a gain, but not by factor of 10 , but just by 1.25 . For this paper, though, a precise measure is not necessary. Wider access is taken as positive. What we find, as is shown in the next section, is that "Big Deals" have led to a major step in the right direction. 


\section{Effects of "Big Deals"}

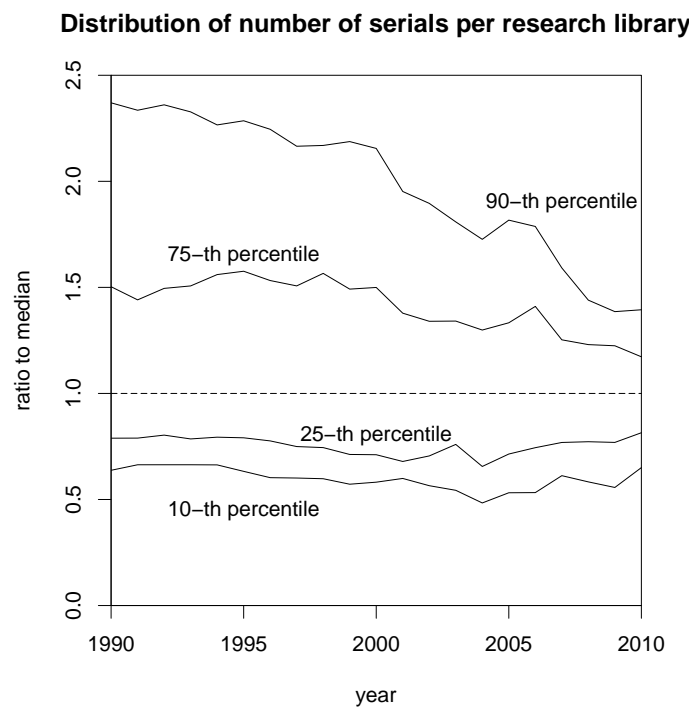

Fig. 2. Ratio of the number of serials received by various research libraries to the median, for 10th, 25-th, 75-th, and 90-th percentiles, ranked by the number received.

ARL statistics for the academic years 1989-1990 through 2009-2010 (depicted in all the graphs as 1990 to 2010), show that the last decade has produced a remarkable increase in availability of serials. This is shown graphically in Fig. 1, which is based on a ranking of the ARL academic libraries by the number of serials they receive.

The increase in numbers of available journals was also accompanied by a notable leveling in availability among ARL members. This can already be discerned in Fig. 1, but is much clearer in Fig. 2. For each year, the academic members of ARL were ranked by the number of serials they received, and the percentiles and displayed ratios were computed. There is a great degree of compression, especially at the top, with the 90-th percentile institutions far closer today to the median than in earlier years. The distribution of library budgets has not changed much over this period ${ }^{3}$, so what we observe is the result of increased price discrimination. Figures 3 and 4 show statistics for the "small" vs. "large" ARL libraries, defined in each year as those below and above the media in terms of total library budgets. (Thus "small" is a relative term, as in 2010 this category included a few libraries with budgets of over $\$ 22$ million.) They demonstrate that the "small" institutions gained more than the "large" ones ${ }^{4}$. The average price per serial received by ARL academic members has plunged over the last decade, to a level last seen around 1990, even in current dollars, without any adjustment for inflation. (Unless stated otherwise, all dollar figures in this paper are in current dollars.)

The growth of the last decade was certainly made possible by improvements in technology, so that huge collections of journals can be made available in electronic versions even 


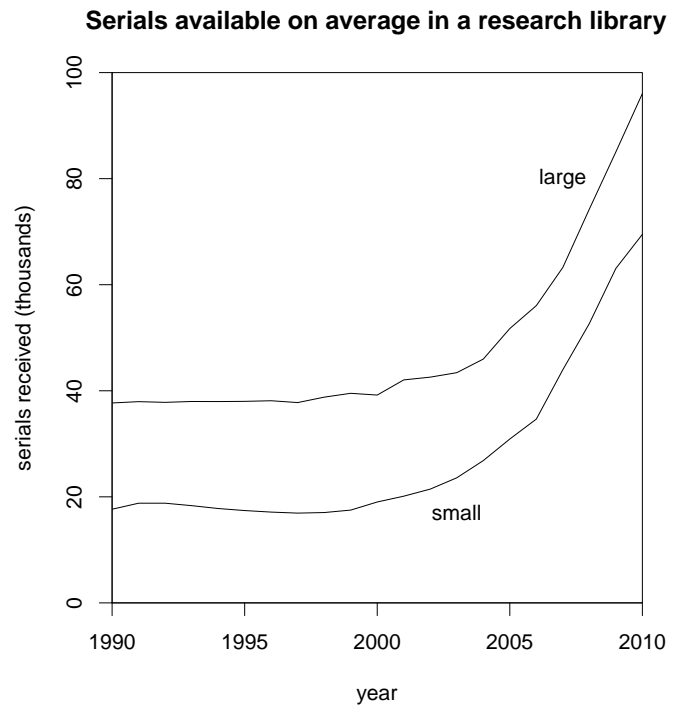

Fig. 3. Average number of serials received in smaller and larger research libraries, 19902010 .

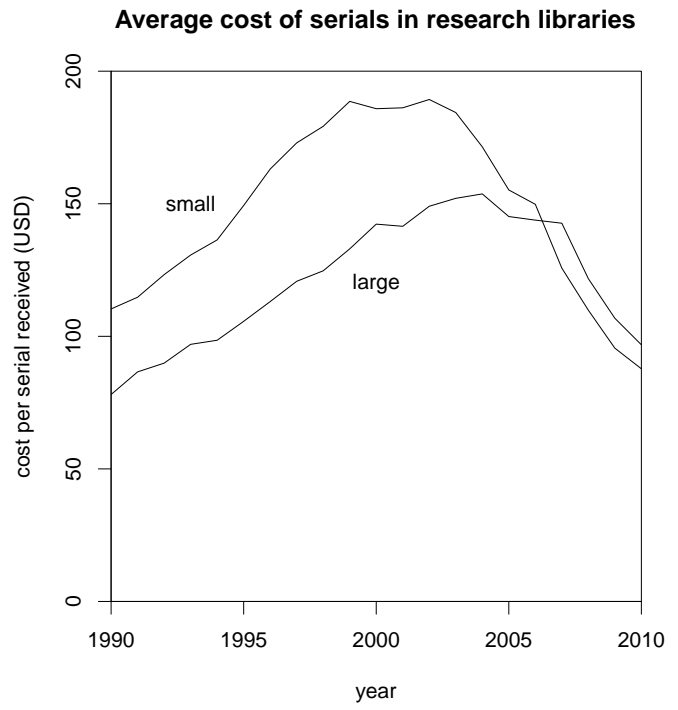

Fig. 4. Average price per serial received that was paid by the smaller and larger halves of research libraries, 1990-2010. (Current dollars, not adjusted for inflation.) 
by libraries that could not possibly hope to house them physically. But much of the credit must be assigned to the reviled "Big Deals," in which publishers enriched their offerings by tossing in many additional journals. This increase in journal availability was not accompanied by commensurate revenue increases. As is shown in the ARL statistics summarized in Section 5, while the growth in spending on serials did outpace the growth in library budgets, it did so by a smaller margin in the first decade of the 21st century than in the last of the 20th.

A serious deficiency of the results presented here is that they tell us practically nothing about the "Big Deal" practices of the large publishers, such as Elsevier, Springer, and Wiley. Those are the publishers who attract the most attention, and they also take a lion's share of the journal spending at libraries. However, they publish relatively few journals. As an example, Elsevier, the largest of these publishers, has just under 2,000 serials [28]. They are disproportionately expensive, and also have disproportionately many articles. However, since ARL statistics only provide the total number of serials in member collections, the contribution of Elsevier is essentially in the noise. What we can observe is basically just the effect of various aggregators. Furthermore, many, and perhaps most, scholars, care only about peer-reviewed journals. There are only about 20,000 to 25,000 of them, and the ARL statistics this paper is based on do not distinguish them from others.

Publishers' pricing practices are not the result of altruism. These practices make excellent business sense for publishers. With electronic delivery, providing access has practically zero marginal cost. From long interactions with libraries, publishers likely have a good sense of how much they can squeeze out of each institution. Once that point is reached, the incentive is to increase usage by everyone at that institution. That way people get introduced and hopefully addicted to new data sources from that publisher, which will make it that much harder for their libraries to pull out of the "Big Deals." Further, making all journals available to all customer libraries serves to decrease the advantages of Open Access. The faculty, students, and staff have the necessary articles seamlessly available (courtesy of the librarians and the library budget), and so are less likely to complain to their colleagues at

other institutions about not being able to find all they need. Therefore those colleagues feel less pressure to get involved in Open Access activities.

In the short (and even intermediate) run, "Big Deals" therefore do promote wider access to scholarly literature, and they do serve to push libraries to be more efficient. Thus what we observe in the ARL libraries is Adam Smith's "invisible hand" producing socially desirable outcomes. In the long run, of course, "Big Deals" do entrench the publishers, their profits, and their inefficiency.

Perhaps the greatest puzzle about the wider availability of journals through "Big Deals" is that it has not occurred much earlier. This has implications for the rest of the economy, and will be discussed later. First, though, let us look at the ARL data, and at some general financial statistics of universities, libriaries, and publishers.

\section{$5 \quad$ ARL and other statistics}

The Association of Research Libraries (ARL) has, as of this writing in early 2013, 126 members. Of these, 11 are public, government, or other non-profit non-academic institutions 
(Library of Congress, Library \& Archives Canada, New York Public Library, ...). Those 11 are excluded from all statistics presented in this paper, since they usually have much wider missions, and are on average far larger in terms of budgets. (The largest budget among ARL members has for a long time belonged to the Library of Congress, which currently spends about 6 times as much as the largest academic library, that of Harvard.)

ARL prepares annual reports on operations of its members, which are available through [9]. They cover academic years from July 1 to June 30, and have in recent years been prepared by Martha Kyrillidou and her colleagues. Thus the report entitled ARL Statistics 20092010 covers the 2009-10 academic year, and was issued in the fall of 2011. It will be referred to in this paper as the ARL 2010 report, and similarly for other years. Almost all statistics in this paper are based on the 1990 through 2010 reports. The 2011 report is now available, but the bulk of the research was done before it was published, so it is not included. However, it does not appear including it would have led to any significant changes in either the statistics or the conclusions.

The membership of ARL is very stable. Over the 1990-2010 stretch, academic members grew from 107 to 115, with just one withdrawal. Although the non-renewing library (Stanford) was large, and the 9 new members considerably smaller, the distribution of library budgets has not changed much. In 1990, the average budget was $\$ 12.99$ million, and the standard deviation was $50.0 \%$ of that. By 2010, the average budget had grown to $\$ 27.49$ million, while the standard deviation only increased to $54.2 \%$, and the distribution curves for budgets (not shown here) were almost identical for those two years. (All figures are in current US dollars, not corrected for inflation. Canadian data is presented in US dollars in ARL statistics.)

ARL statistics are an unparalleled resource of detailed information about research libraries. They go back to 1907 (the famous "Gerould Statistics" of the first few decades). They are very carefully collected, and are a result of the very open and collaborative culture of librarians. Still, in spite of strenuous attempts at uniformity (and use of National Information Standards Organization guidelines), they are not perfect. The voluntary nature of reporting, the presence of legacy systems and procedures, and sudden local changes leads to some obvious anomalies. As an example, the expenditures by Harvard on acquisition of serials reached $\$ 10.5$ million in the 2004 report, then came down to $\$ 8.4$ million in the 2009 report, and then skyrocketed to $\$ 15.3$ million in 2010 . Yet another anomaly was the number of serials received by the University of Michigan, which was reported as 67,554 in 2004, 124,809 in 2005, 118,654 in 2006, and 71,788 in 2007. Both cases likely arise from changes in categorizations. Such anomalies were ignored in preparing the statistics in this paper, in the expectation they would not affect overall averages much. (In a few cases, missing values were interpolated.) Anomalies of this nature do not appear to be present in total library budgets, nor in the amounts spent on acquisitions. This is likely the result of stricter accounting standards and controls for monetary expenditures.

The serial counts shown in the figures are those for the total number of serials reported as being received by various libraries. The serials that are purchased are a more relevant figure. However, not all libraries report this figure separately, so in order to have fuller coverage, the total serial count was used. That is not likely to cause a major distortion, 
as among those institutions that do break out the purchased serials figure, the fraction of serials that were received but not purchased was $24.1 \%$ in 1990 and $27.6 \%$ in $2009^{5}$.

For all statistics, calculations were done separately for each year. Thus the "small" category of libraries in Fig. 3 included all libraries whose total budget was at or below the median for all budgets for a given year.

One of the major deficiencies of ARL reports is that they seriously understate the internal costs of libraries. They count only the direct pay of employees, and not any of the health care or retirement benefits those employees receive. ARL reports also do not include most of the maintenance costs of library facilities (heat, electricity, cleaning, ...). Given the enormous variation in how universities account for such costs, it would indeed be hard to come up with a uniform reporting standard that could be implemented easily, so these omissions are understandable. Still, what they mean is actual total library costs are likely about $25 \%$ higher than the budgets given in the ARL reports (as confirmed by some correspondence with librarians).

\section{Universities, publishers, and libraries}

The ARL has statistics showing library budgets as fractions of total university budgets for a sizable collection of their members [10]. The chart for the 40 members that have reported since 1982 shows an inexorable decline in this ratio, from about $3.7 \%$ to a bit under $2.0 \%{ }^{6}$. As was mentioned above, more accurate accounting would inflate the cost of libraries by about $25 \%$, so the decline was from a level of about $4.5 \%$ to about $2.5 \%$. But the trend and size of the decline would not have been affected materially by this adjustment.

Thus libraries have been getting a shrinking part of the entire budget, and there would be no journal crisis had they just maintained their share from the 1970s. However, this has to be put in context.

Universities have an insatiable desire for more funding. They are complicated entities, and need to support many activities. Retirement bonuses for administrators, buyout packages for heads of athletic departments, fancy big football fields, and of course fancy salaries for football coaches, all compete for funding with a variety of other categories, including libraries, faculty salaries, classroom and lab buildings, mental health counseling for students, and many other cost centers. Note that the $\$ 2$ million or so that a typical large university paid for access to all Elsevier journals in 2007 would not be enough to pay for a single prominent football coach.

A very remarkable fact is that, in spite of all the wailing and gnashing of teech, universities have been extremely successful in obtaining more funding. This is surely the result of the observation cited earlier in the Introduction, that education is becoming ever more important as technology and the economy advance. Table1 shows statistics for ARL members in the last two decades (with CPI denoting the main Consumer Price Index for the U.S. ${ }^{7}$. Their budgets have grown far faster than the economy as a whole. And so have library budgets, even though they grew more slowly, and not as fast as spending on library acquisitions.

[Note: The growth rates for total budgets for ARL member universities are suspiciously large, and will need to be verified. They are based on data from the ARL for 1990, 2000, and 
Table 1. Annual compound growth rates.

\begin{tabular}{lrrrrrr} 
year & US GDP & US CPI & $\begin{array}{r}\text { university } \\
\text { budgets }\end{array}$ & $\begin{array}{r}\text { library } \\
\text { budgets }\end{array}$ & $\begin{array}{r}\text { library } \\
\text { purchases }\end{array}$ & $\begin{array}{r}\text { serials } \\
\text { purchases }\end{array}$ \\
\hline $1990-2000$ & $5.55 \%$ & $2.85 \%$ & $6.83 \%$ & $4.65 \%$ & $6.16 \%$ & $6.93 \%$ \\
$2000-2010$ & $3.85 \%$ & $2.53 \%$ & $8.70 \%$ & $3.74 \%$ & $4.84 \%$ & $5.64 \%$
\end{tabular}

2009 (since figures for 2010 were not available, so a 9-year annual growth rate was entered in the 2000-2010 line). Only figures for the 89 ARL members for which data were given in the ARL tables for each of those three years were used. Some of the figures in those tables seem anomalous. For example, the budgets of the University of Connecticut, University of Michigan, University of New Mexico, Ohio State, Temple, University of Utah, University of Virginia, and Western Ontario are all shown in those ARL compilations as increasing by more than a factor of 3 from 2000 to 2009. This is rather implausible, unless it corresponds to some major changes in accounting, such as sudden inclusion of revenues from affiliated hospitals, and if it does, this would be misleading. Still, there have been other reported statistics of higher education budgets in the U.S. outpacing not just inflation, but GDP growth and sometimes even medical sector growth, so whatever the right figure in that column, it is likely to be high.]

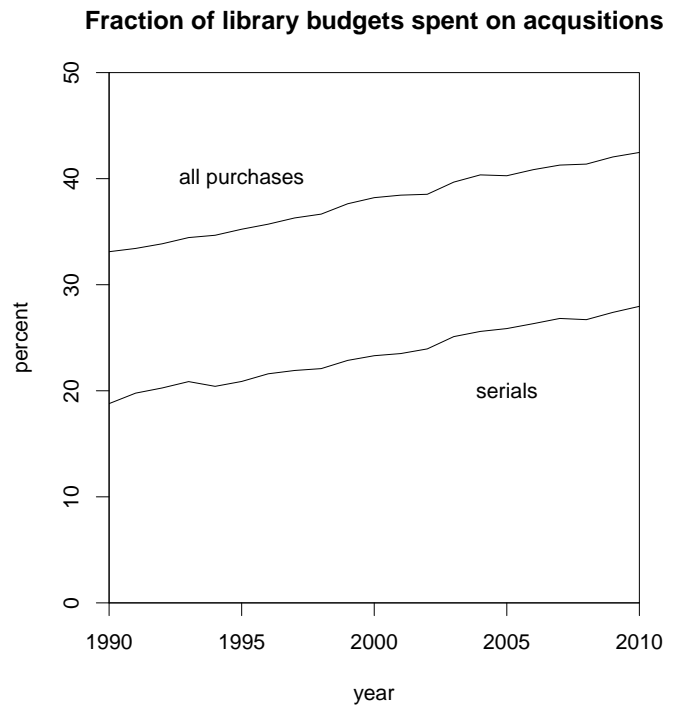

Fig. 5. Fraction of library budgets devoted to all acquisitions and to purchases of serials.

One result of the trends shown in Table 1 is displayed in Fig. 5. The share of library budgets that goes out in purchases of books, journals, and databases has grown substantially, from $33 \%$ in 1990 to $42.5 \%$ in 2010. (If we correct for the undercounting of library budgets cited before, the growth is from about $25 \%$ to about $33 \%$.) Further, all of this 
growth is accounted for by serials. Books and other materials have just about held their own (with books shrinking at the expense of the rest).

Collectively, academic members of ARL had budgets that added up to $\$ 3.16$ billion according to the 2010 report, so that their actual costs were likely close to $\$ 4$ billion. Of this, $\$ 1.34$ billion was spent on outside acquisitions, and $\$ 884$ million of that on serials.

The entire scholarly publishing market, as measured in terms of publisher revenues, is someplace around $\$ 20$ billion per year ${ }^{8}$. Of this, journals account for $\$ 8-10$ billion.

There are various estimates for the number of scholarly articles published each year, although it does seem to be agreed this number grows by between $3 \%$ and $3.5 \%$ per year. The report 84] had a figure of about 1.5 million English-language peer-reviewed being published in 2009. There are some estimates that are higher, around 2 or 2.5 million, and they may also be correct, in that they may include non-English publications as well as some serials that are not peer-reviewed. This paper uses the round figure of 2 million for simplicity.

\section{Lower cost models}

Revenues of $\$ 10$ billion and 2 million articles mean an average cost to society of the scholarly publishing system of about $\$ 5,000$ per article. This does seem to be typical. Note that this does not differ much from the estimate made almost two decades ago [56] of about $\$ 4,000$ per article.

If we consider the Reed Elsevier annual report for 2011 [28], we find that the science and technology segment of the Elsevier business unit had revenues of about $\$ 1.7$ billion, and published around 240,000 articles. Since that division also published books and engaged in other activities, if we assume $\$ 1.2$ billion as the journal revenues, we obtain a figure of about $\$ 5,000$ per article. Many professional societies operate at similar levels. For example, the American Mathematical Society had journal revenues of $\$ 4.7$ million in 2010 , and published 873 articles, for revenues of $\$ 5,400$ per article ${ }^{9}$.

Most of the arguments for Open Access are valid irrespective of the costs of publications, and are based on the public good, efficiency of research, and similar considerations. However, the possibility of moving to dramatically lower cost structures does make a switch to new business models much easier to perform. It has been clear for two decades that much lower costs in scholarly publishing are possible, but with some exceptions, little has been done to the bulk of the literature to move in that direction.

As a point of contrast and information, the costs of running the arXiv preprint server are under $\$ 10$ per article that is submitted each year. There is still some cost. Various problems arise with submitters (most handled by unpaid volunteers who do some minimal screening to eliminate inappropriate postings), basic software changes have to be handled, new features need to be put it, compatibility has to be preserved, and so on. However, with minimal human intervention costs can be very low. Once experts get involved, costs can mount up quickly. As an example, the MathSciNet reviewing operation of the American Mathematical Society [3] collects revenues of about $\$ 100$ per reviewed paper, and, depending on how various expenses are allocated, costs possibly not much more than half 
of that, or about $\$ 50$ per paper. This time subject experts with PhDs in the appropriate disciplines are involved, as well as myriads of unpaid reviewers, and publishers cooperate in providing metadata and other information. Still, this cost is about two orders of magnitude lower than current average cost of an article. That serves to disprove frequent claims of publishers that metadata provision is expensive.

Can one operate high-quality scholarly journals for less than $\$ 5,000$ per article? That this issue is still debated is a good introduction to a major theme of the rest of the paper, the slow rate not just of actual change, but even of information diffusion in our society. Almost two decades ago various investigators estimated that between $\$ 300$ and $\$ 1,000$ per article should be sufficient for good service [56]. Since that time mountains of evidence have accumulated to support that conclusion. There are now numerous journals operated by their editors, without any explicit monetary flows. Further, we have, among others, the Edgar and Willinsky study [26] of almost 1,000 journals that use their Open Journal System (in use by about 5,000 journals in all) which found the first copy costs (which is essentially all that matters if one considers purely electronic publishing) of $\$ 188$ per article. Clearly, many of these low-cost ventures do benefit from implicit subsidies (such as free use of university information technology infrastructure), and would not scale to larger journals without having to pay for various types of administrative assistance. Still, when we have examples of 10x cost savings, even a doubling of the cost to pay for all those extras still leaves us with a $5 \mathrm{x}$ cost advantage.

That lower costs were possible was obvious even three decades ago, since the costs per article varied wildly between publishers. This showed that costs were not a matter of unavoidable necessity, but of market power, choice, and inertia. This has become far clearer since then. There are many cost reductions that are feasible and desirable. Let us consider some.

The first step is to abandon print entirely, and publish strictly electronically. That will eliminate the expenses not just of the print operation, but also of the preparation for print. Once that is done, it will be much clearer that there is much more that we can choose to economize on. For example, why devote a lot of effort to ensuring consistency in layout, reference styles, etc. in a purely electronic journal? (Those activities do consume extensive effort even in low-cost serials, see, for example, the data for the Open Journal System journals [26].) In a printed version, it might have made some sense, but in the modern online environment, where readers follow threads from one journal to another, this uniformity contributes little.

Some of the terrible waste that is involved in scholarly publishing involves no money, but extra work for authors. For example, some journals insist that not only the final accepted versions of papers adhere to their chosen format, but that even initial submissions do. This is not just wasteful, but silly. Yet it persists, and provides yet another illustration of the inertia in academic publishing.

To get to the lowest ranges of costs, one can also eliminate most of copy editing. The quality of author-prepared manuscripts that I find at the arXiv and SSRN preprint repositories is almost always completely adequate from my personal perspective. (The same is true of the conference proceedings that ACM and IEEE publish, where the authors are 
responsible for producing the files using the publisher-supplied style files.) As a reader of scholarly journals (and I read a lot, in a variety of fields) I find copy editing useless, although admittedly this is an extreme opinion.

As an author, I find that copy editing subtracts value, by forcing me to do extra work, usually for no good reason, and often to correct what the copy editors have done. As just one example, a recent set of proofs I received resulted from the publisher editing the manuscript, and, among other things, changing the reference style from the one my coauthor and I used in the preprint to the official one of the publication. Although I loathe that style, the move was understandable, as our contribution is to be a chapter in a book, where uniformity is expected. However, the editing introduced all sorts of grammatical and stylistic errors. The result was that my coauthor and I spent more time correcting the proofs than we would have spent getting things right in the first place, had we been told what was wanted.

Thus my firm conviction is that one can publish scholarly articles at much lower cost than is done today. One can do it even if one does a moderate amount of copy editing, as the Edgar and Willinsky data [26] shows.

The $\$ 800$ million that just the ARL members alone spend on journals is about $\$ 400$ for each of the 2 million or so articles that appear each year. And $\$ 400$ should be plenty, as was forecast two decades ago, and as is demonstrated by many respectable journals. Yet the world is currently paying about $\$ 5,000$ per article. The question is whether we can get there from here.

\section{Competition between libraries and publishers}

The evolution of academic information systems is viewed most fruitfully as dominated by competition between publishers and libraries. However, one should not neglect the role of an increasing variety of other players, as this sector evolves. A century ago, libraries and publishers were basically the only significant players, and there was a strict separation in their functions. Today, the lines are blurry. It used to be that publishers put out books and journals, and libraries preserved them for posterity. Publishers might keep some copies of old issues in their inventory, but were not obliged to, and had little incentive to reprint. But with electronic publications, it is far more efficient and effective to have the publishers maintain the files, migrate material to new formats, etc. (I am ignoring here issues such as censorship, which is far easier to carry out on a publisher's few mirrors than it is on a thousand libraries.) It does not have to be a publisher that does this, as the Internet Archive and Google Books demonstrate. And there are many other players in this expanding arena, from high performance computing centers that increasingly handle large data sets, to commercial organizations curating genomic databases. That is not a surprise. Information and education are becoming more important to society, so it is to be expected that more will be spent on it. This is the same phenomenon that is driving up spending on medical care. Although various reforms have been carried out and others are planned, the move towards more of the economy being devoted to health is worldwide, associated with rising standards of living. Any increases in efficiency there are likely to be swallowed up in new treatments, or just in more treatments for an aging population. Similar trends appear 
likely to operate in education. While the traditional functions of librarians and publishers are obsolete, new opportunities are arising for intermediaries between researchers and other researchers, or between researchers and the wider public.

There are many interesting statistics at [9] demonstrating decline of the traditional functions of libraries. Thus between 1995 and 2010, the number of students at ARL institutions grew by $33 \%$ (with the ranks of teaching faculty and graduate students climbing $15 \%$ and $43 \%$, respectively). The only category of library services involving physical material that showed growth was interlibrary loans, which climbed $92 \%$. This reflects libraries concentrating their budges on serials, and giving up on trying to keep up with the growth in the number of new books being published. In other categories, initial circulation (i.e., excluding renewals) of physical volumes dropped by $42 \%$. Thus it is a gross exaggeration that "nobody uses the library anymore," as one sometimes heard from faculty or students. But the decline in borrowings per student by more than half is telling. What is perhaps most surprising is that the number of requests for reference assistance dropped by $66 \%$ in absolute terms, as is shown in Fig. 6, and thus by about $75 \%$ on a per-student basis. This is certainly a core competency of librarians, and they are great at navigating the torrents of electronic information, as well as providing guidance to the use of traditional printed sources. However, it appears that Google, Wikipedia, publisher databases, and the like are "good enough" for most scholars, and that the convenience of around the clock access from anyplace outweighs the higher quality that librarians provide.

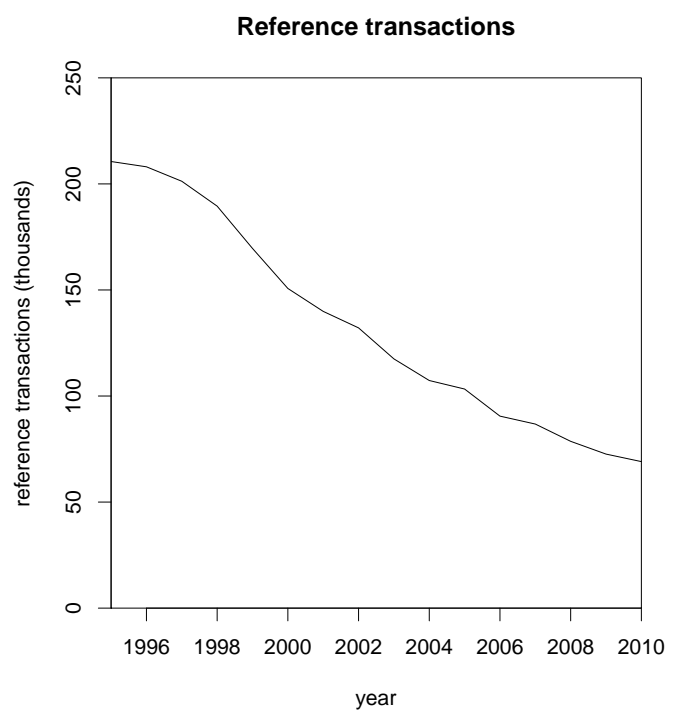

Fig. 6. Average number of reference transaction in reporting research libraries, 1995-2010.

The declining reliance on reference librarians is intriguing. In many, perhaps most, of the areas of the economy we see great willingness to pay more for what is perceived as the very best, even when the margin over second best is extremely slight or illusory. So the very top athletes, artists, and lawyers (and sometimes even academics) see their pay 
skyrocket, while the crowds of competitors who are almost as good languish in obscurity and often penury. Ranks of applicants to top-ranked universities grow tremendously, even though there is little evidence this leads to more successful careers. But librarian skills are apparently not perceived in this same light.

What librarians could have done, and might yet do, is discussed later. First, though, let's consider publishers. They have moved faster than librarians to adjust to the new world, as was to be expected [62]. They have many options for maintaining their leaderships (as well as their profits) in the future. A transition to Gold Open Access (in which authors, or their funding agencies, pay the publishers and the articles are make freely available) might not be a threat by itself, but rather a possible opportunity to increase revenues if one can sustain subscriptions, say in a hybrid model. Even if publishers are forced to lower their revenues, they could maintain their profits by making some of the moves discussed in Section 7, such as giving up entirely on print, decreasing the amount of copy editing, and abandoning the requirements for uniform style in each journal. They might also increase their profits while keeping revenues steady, by implementing some of these moves.

The basic and very promising approach open to publishers is to continue marginalizing libraries by extending the reach and scope of "Big Deals." The consortium model, in which groups of libraries cooperate to get access to a "Big Deal" is already common, and can be pushed further. The ultimate situation might be national "Big Deals," where some toplevel bodies pay for access for everyone from a nation. Enlarging the "Big Deal," especially through further mergers, but also by including additional information sources, can serve to create packages that simply could not be dispensed with. The most obvious move in that direction (which is already taking place to a small extent) is to make books, both current and old ones, a part of the "Big Deal." (Recall that the process of digitizing old printed materials is extremely inexpensive.)

While it is a little puzzling that journal "Big Deals" have been so slow to spread, the slow rate for inclusion of books is much more understandable. For several decades now, the principal method of using scholarly journals has been to scan a multitude of articles, photocopy the ones that appeared to deserve more careful study, and work with those photocopies. Hence the transition to all-electronic journals is relatively seamless, with the photocopying being replaced by printing. It is also far more efficient, as one does not have to go to the library, and handle awkward bound volumes, and instead prints in one's own office or study. Even so, there are die-hard traditionalists who continue to insist that nothing will replace the traditional methods. However, their ranks are decreasing. Printed books, on the other hand, have many more adherents. They are traditionally used in ways substantially different from that of articles. It would have been difficult a decade ago, for example, to persuade scholars to give them up. However, improvements in technology have led to very nice ebook readers and more general tablet computers, and there is a rapid move in the population as a whole towards ebooks. Scholarly publishers therefore have a chance to jump on the bandwagon and also to speed it up. By digitizing their current offerings as well as their old out-of-print volumes, they can provide better service to readers, and reduce the need for libraries. Furthermore, with the improving quality of print-on-demand services, it is still possible to cater to those who insist on paper copies. 
Making books as well as back issues of journals widely available in electronic forms could also help in indirect ways. In the traditional print world, it would have been a major disaster for a small institution, say Reed College, to be given a duplicate of all of the Harvard libraries' physical collections. There simply would not have been the space or personnel to handle such riches. But, based on experience, we can be sure that Reed College faculty and students would use all that is at Harvard if that were available online. And once Harvard faculty see their colleagues at Reed relying on ebooks instead of hard copy volumes, their resistance to doing the same will diminish.

It would also be wise for publishers to overcome their reluctance to tamper with copyrights, and to forcefully push for legislative solutions to the orphan works problem. Orphan works, which are those that are under copyright, but whose copyright owners cannot be located, provide a major justification for the existence of large physical collections in libraries, as that is the only legal way to make such works accessible to the public. To the extent orphan works are digitized and made freely available, the need for library facilities (both physical and personnel) declines. That would make it easier for publishers to appropriate even more of the resources now going to libraries.

What about libraries? They are handicapped in the competition with publishers by several factors, see [62]. One of them, that they have the bulk of the resources, and are thus a fat target, is a strength as well. At least in principle it makes possible revolutionary changes. In particular, as was shown earlier, just the external journal purchases of the ARL libraries alone could provide Open Access publishing for the world's entire scholarly literature. Had libraries thrown their resources enthusiastically behind new, low-cost Open Access journals, perhaps the current scene and the unfolding future sketched here would have been different. But that would have required many research partners willing to put their energy into the enterprise (certainly a very doubtful proposition, given the inertia in the academic system), and the willingness of librarians to cannibalize their bread-andbutter operations. Certainly librarians present a classic case of Christensen's “innovator's dilemma," pressed to maintain traditional services, and therefore slow to embrace new ones. As an example, digital libraries have been discussed in the library literature for decades. Further, the amount that ARL libraries spend in a single year on acquisition of serials would have sufficed, with plenty left over, to digitize all their standard books and journals that are out of copyright ${ }^{10}$. Yet it was outside efforts, in particular the Gutenberg Project (the early pioneer, almost forgotten), Google Books, and the Internet Archive, that led the way ${ }^{11}$. And thus today we do see libraries moving towards support of Open Access, beginning to pay some author submission fees, and providing financial and management support for inexpensive new journals. But the moves are slow (reflecting, perhaps, the hesitant embrace of Open Access one detects in [36]), and may not be enough to prevent further publisher encroachments.

We also see libraries moving into other services, such as providing long-term storage for publications, data sets, and so on. However, there they are competing not just with publishers, who also see the opportunities, but also other organizations, such as campus information technology units, high performance computer centers, and a variety of new commercial startups. The opportunities are many, but so are the competitors. 


\section{The future of the economy}

Scholarly communication and the "Big Deals" are interesting not only in their own right, but also because they provide interesting perspectives on the development of the general economy. As one example, one of the reigning mantras of the Internet bubble was that of "friction-free capitalism," a term that was coined by Bill Gates, and one that he was very proud of [32,33]. Barriers would fall, middlemen would be disintermediated ("[o]ften the only humans involved in a transaction will be the actual buyer and seller," [32], p. 158), and the economy would be far more efficient. Yet there was a certain implausibility from the start about the vision of "friction-free capitalism." How could it be reconciled with the rich profits Microsoft was making (and continues to make today, even in the face of competition from free Linux and other operating systems, and even as PC sales sag)?

There were many arguments that while the economy would get more efficient, it would depend crucially on "speed bumps" 58. (Such speed bumps were actually mentioned briefly by Bill Gates in [32], p. 234.) Those speed bumps might take a variety of forms, from various methods for increasing switching costs to patent and regulatory barriers. (It is noteworthy to observe the growth in the ranks of lobbyists in Washington, especially those representing the technology industry. When it is only the inertia of habit that induces customers to stick to a particular web site for browsing or shopping, any speed bumps matter, and court injunctions, say, become giant speed bumps.) Mergers and acquisitions, such as those witnessed in academic publishing over the last couple of decades, can be viewed as attempts to create bigger speed bumps, in which refusing to deal with a particular publisher becomes unthinkable. (That lets publishers get away from the constraints imposed by models such as those studied in [50].)

Among speed bumps, many can be categorized as part of confusology. Scott Adams back in 1998 had the prescient idea, in one of his Dilbert books, that "Companies form confusopolies to make it impossible for the average individual to determine who has the lowest price," [2], p. 161. Let us use the word confusology for the more general art of befuddling customers. It is an art that flourishes, and financial analysts have claimed recently, for example, that "[f]or years, the telecom industry has thrived on obfuscation" [52]. (In view of the high demand for expert practitioners in confusology, it is strange that academia has not yet developed courses in it.) A very elementary form of confusology is to pollute the consumer website data, where an "investigation has uncovered fake reviewing on an almost industrial scale, with companies paying offshore contractors to post numerous glowing accounts of their activities, yet maintaining they are from unbiased consumers" [77.

With the benefits of hindsight, we can see that the economy has become more efficient, and many intermediaries have been disintermediated. There are many news stories about modern technology empowering customers, cf. [14,24]. Brick and mortar stores that have not mastered confusology sufficiently do suffer from shoppers who look and test, and then comparison shop at Amazon and other places on their smart phones, often right in the store. But they are likely to soon learn, or else will go out of business. Two stories in the same recent issue of the New York Times illustrate both the problem (for sellers) and the obvious potential solutions [17,68]. One article discusses apps available to customers that alert them to sales on goods and services they are interested in, to compensate for 
the rapidly changing prices [17]. The other, though, shows how even in the world of highpriced art, where auctions, which are acclaimed by economists as an ideal tool for price discovery, are a basic sales method, sellers manage to confuse the scene, even though the buyers are usually very wealthy and thus presumably sophisticated individuals [68. Thus we can expect (and already see in many situations) sellers avoiding the disadvantages that the stores in [17] suffer by moving to offering personalized discounts, etc.

Thus on balance it is not clear that the economy has become more transparent, or that the role of intermediaries has diminished (even though the dominant ones may now have different names, like Google, eBay, and Amazon). Auctions for ads by Google are a triumph for theoretical economics. But they are imposed by Google, which has an interest in having a transparent market that will maximize its revenues. Elsewhere, we find dramatically different pictures. By far the largest industry is health care. It is also among the fastest growing, and there is no denying that it is improving lives (although not as fast as it is swallowing resources, it seems). It is also among the most opaque. (The discussion here, as well as in most of this paper, is very U.S.-centric, and various parts of the argument and evidence may not apply to other countries.) An individual, even one not dealing with an emergency, who attempts to deal with this system encounters a bewildering morass, with prices unobtainable or incomplete, and varying wildly between different providers, and cryptic codes in bills that conceal obscure and unexpected charges, e.g. [71]. Not paying such bills promptly, though, often leads to encounters with abusive bill collectors. A standard way to mitigate such problems, for those affluent enough, or with jobs that provide good employee benefits, is insurance. But that introduces a new (and expensive for society) level of intermediaries that also are good at confusology. There are all those "reasonable and customary fees," that do not necessarily seem reasonable, and whose determination is a closely guarded secret of the insurers (although a few lawsuits have led to some reform and transparency). An experienced business journalist made "more than 70 phone calls to 16 organizations" and yet was still not able to find out how much he would have to pay for a prescription drug that keeps his cancer under control [43]. Digital health records should eventually lead to better medical care. However, their spread was pushed by the government largely on the promise of reducing costs. As of now, "[w]e've not achieved the productivity and quality benefits that are unquestionably there for the taking," and "evidence of significant savings is scant, and there is increasing concern that electronic records have actually added to costs by making it easier to bill more for some services" [1].

Medical care is just one example of extensive confusology. The financial industry is another. During the Internet bubble, banks were often seen as obsolete intermediaries that were at best doomed to shrink. Instead, along with the rest of the financial industry, they have prospered. One of their routes to prosperity was creation of confusing products. Acclaimed by economists and regulators as instruments for spreading the risk to those able and willing to bear it, they ended up in the hands of those who understood them the least. Even the most visible financial markets, with all the rules and regulations, were visibly murky even before the crisis of 2008 [70], as much of the trading was carried out in opaque venues, out of sight of the public. More recently we have learned that the Libor rate, perhaps 
the most prominent financial benchmark, had been manipulated for years. The growing complexity of our interconnected world appears to allow for increased manipulation and inefficiency. Even regulators, with access to far more information than the general public, much less the general public, often fail to understand what is happening. Large banks, which created and helped conceal many of the dangerous financial practices that brought the economy to the brink of precipice in 2008, had to be rescued because they were Too Big to Fail. In the process, the surviving ones have become Much Too Big to Fail, and in spite of pledges of reform, appear to be just as opaque as before [66].

It is not just profit-making corporations that rely on such methods. Higher education institutions are expert practitioners of confusology. University budgets are opaque, and little comparative performance data is available for different institutions. While affirmative action on grounds of gender or race does attract substantial scrutiny, the extent of athletic or "legacy" preferences usually only catches public attention when some scandal erupts. And higher education pricing is also increasingly confusing. While tuition is rising rapidly, so is "financial aid," which at private universities in the U.S. now amounts to over $40 \%$ of tuition revenue. Furthermore, there is an increasing amount of bargaining between parents and institutions.

The commercial higher education sector is an extreme example. An investigation by a U.S. Senate committee found that among 30 for-profit colleges, "an average of 22.4 percent of revenue went to marketing and recruiting, 19.4 percent to profits and 17.7 percent to instruction" [44]. Might seem shocking, but figures for non-profits might also turn out shocking, if they were available. In general, in many sectors of the economy the basic cost of providing goods and services is often dominated by various overhead expenses.

From this point of view, academic publishing is only catching up to the general trends. Whereas in the old print-only world, pricing was fairly simple, now it is concealed by the non-disclosure clauses of the "Big Deal" contracts. And a new group of intermediaries has arisen who, for a fee, and based on their private knowledge of the market, help libraries negotiate improved "Big Deals." Publishers use their superior knowledge of the market as well as of usage patterns to argue that the deal they are offering a particular institution is the very best deal in the world. (And it often is, as the availability of many measures makes it possible to custom tailor metrics that show just about anything one can wish.) Thus it is hard to tell what is happening.

\section{The "Tom Sawyer economy" and control of chokepoints}

A frequent complaint by researchers and librarians is that publishers profit from the unpaid labor of scholars who write papers and referee submissions. Yet that is an increasingly common feature of the economy, and scholarly publishing may be viewed as a forerunner of this trend.

In the stock market, for much of 2012, the most valuable company in the world was Apple. It is also among the enterprises most admired by the general public. Its dominant position is due largely to the iPhone and the iPad, and a key reason those products were embraced enthusiastically by the world is the multitude of apps that are available. Those 
apps are mostly produced by independent developers. Apple boasts that these developers have earned $\$ 6.5$ billion over four years [80]. But there are about 300,000 of these developers, so on average they have earned all of about $\$ 20,000$ on average from their creations, and this was spread over four years. In the meantime, in just the last quarter of 2012, Apple had revenues of $\$ 54.5$ billion, with net profits of $\$ 13.1$ billion, the bulk derived from the iPhones and iPads. So it is a partnership in which Apple gets almost all the profits. What the app developers get is bragging rights, hopes of striking it rich, and an occasional bonanza, to keep the game going.

The Apple app developer situation is characteristic of many of the most visible recent high-tech success stories. Facebook and Google derive their value from the activities and contributions of their users. They only provide the basic infrastructure for interaction.

The value of crucial control points in extracting value was already demonstrated by Intel and Microsoft in the PC industry. It was a common observation that by controlling the chip architecture and the operating system software, respectively, this duo was earning monopoly profits, while the rest of the industry had to be content with commodity status. Today we are further along the way to what we might call the "Tom Sawyer economy." In Mark Twain's classic, Tom Sawyer, condemned by Aunt Polly to a day of hard labor, manages to inveigle neighborhood boys into paying him for the privilege of doing this work. While few businesses have attained this pinnacle of success, many have come close. For example, Angie's List relies entirely on user-generated material, but charges for access to it. Among others in a similar situation is, of course, academic publishing.

\section{Privacy and the surreptitious spread of price discrimination}

That the University of Michigan paid $\$ 2$ million for the same unlimited access to all Elsevier journals that the University of Montana got for less than a quarter of the price is an excellent illustration of an extremely important, ongoing, and so far seldom discussed development in our economy. That is the growth of price discrimination.

There is nothing nefarious about price discrimination. It is a basic technique that has been practiced for millennia, and its theoretical foundations, which demonstrate its frequent benefits in stimulating economic activity, were first elucidated by the French econoengineers of the middle of the 19th century [27]. Price discrimination by itself is not the ultimate goal in commerce. Rather, price discrimination is a tool for maximizing revenues and profits. (Some techniques, such a the bundling represented by "Big Deals," are viewed most productively as forms of price discrimination that avoid the necessity of costly, intrusive, and objectionable fine-scale pricing.) First degree price discrimination, in which each customer is charged the maximal amount that customer is willing and able to pay for a particular good or service, is the ideal. However, for a long time it was regarded as mainly a theoretical construct, almost impossible to attain (except, to some extent, in cases, such as that of the income tax, where governments with coercive powers obtain detailed financial information from taxpayers under penalty of jail). The Internet, however, is making what was unattainable increasingly feasible.

The Internet, especially in its wireless incarnation, enables sellers to do two things that have been difficult in the traditional brick-and-mortar world. Both are needed to enable 
first degree price discrimination, and both require erosion of privacy. One is to find out how much each individual purchaser is willing to pay. The other is to control usage, which prevents arbitrage (in which a person able to obtain a low price resells the good or service to a person who would be charged a higher price by the seller).

The basic theory of the standard Homo economicus economic model, as well as results from psychology, behavioral economics, and especially history, lead [58,64] to the theory that the incentive to price discriminate is the driving force behind the erosion of privacy, and to numerous predictions, such as:

- there will be no limit on the extent of privacy invasion attempted by sellers

- the public will be very sensitive to privacy erosion

- the public will be extremely sensitive to price discrimination

- price discrimination will spread slowly and primarily in concealed forms

- the public will not resort to technical means for protecting privacy, but will call for government intervention

- governments will play ambiguous roles, often pretending to protect privacy, but frequently acting to facilitate price discrimination

Recent news stories provide nice illustrations of these points. The account of how Target deduces from a customer's purchases that she is pregnant, and starts sending her ads for infant care items, sometimes even before her family learns of her condition, attracted considerable public attention [22]. (Rather characteristically in this area, Target stopped cooperating with the reporter even before the story was published, surely out of concern about such public attention.) But the logic of this move is clear. It is also clear that there are incentives to move even earlier, especially once other retailers start competing in this arena. Why wait to deduce the fact of pregnancy from purchases? If one can get hold of information about the customer's condition, say from visits to physicians, or from health care monitoring services, why not start then? Or better yet, if one can monitor her voice or email communications with her "significant other," one can start a campaign even before she gets pregnant.

Companies detected in such practices invariably claim they do not care about "personally identifiable" information, so that, for example, they would be sending out ads for infant care products to the class of women who might be pregnant. This excuse of not having individual identifications was widely accepted, not just by industry apologists, such as the authors of [73] (who claimed in several places that "[a]dvertisers have no interest in the identity of individual customers"), but also by more careful scholars, such as D. Solove, who opined in 2001 ([79], p. 418) that "[s]ince marketers are interested in aggregate data, they do not care about snooping into particular people's lives." But such claims are ever harder to sustain in the face of data brokers that "are increasingly tying people's real-life identities to their online browsing habits," so that a car dealer greets a potential customer with detailed information on what car models and accessories that customer had investigated on the Web [82]. And would such information lead the dealer to offer the customer an especially low price?

Public sensitivity to such practices is shown by the strong negative reactions to the discovery that Orbitz was showing to Mac users more expensive hotels than to PC users [48]. 
This was actually a very mild move, as even the Mac users had access to the lower priced hotels displayed to PC users, it's just that they were not displayed at the top of the screen. Still, this incident does demonstrate public concern, and makes sellers aware they are playing with fire when they engage in such practices. That is why price discrimination is practiced quietly, and mostly in mild forms so far [51,83]. But we can expect to see intensification of such efforts, both as part of an arms race, and also as ways to probe how much the public will tolerate, and to accustom the public to such practices.

Many of the design choices in services and goods that we observe are likely influenced by the price discrimination incentive. For example, the push for "The Cloud" places people's activities under far closer scrutiny of the operators of such clouds. That provides more data about customer's interests and willingness to pay, and also allows for monitoring of usage to prevent arbitrage. The excitement about mobile technologies is likely also stimulated by the implicit hope that more information and control over user's activities will translate into large profits. The concerns that many investors and financial analysts express about lack of effectiveness of mobile ads may thus miss the point, or be of only short-term significance. The real promise of the always-connected mobile life for service providers is that they might get more control over their customers.

As has often been noted, the public concern about privacy is an unfocused one. People complain about their loss of privacy, but are not willing to do much about it, and usually cannot articulate what it is they are upset about. Framing the issue in terms of price discrimination brings clarity to the discussion. On one hand there are the well-understood benefits of this practice, on the other hand is its assault on the sense of fairness (which appears not to be unique to Homo sapiens, as even some monkey have been shown to share it), and the potential demise of the market economy, as the demand-supply curves so beloved of economists become irrelevant.

Academic publishers' "Big Deals" provide a very illuminating example of the spread of price discrimination. That it should happen is natural. Technology is enabling it, the economic incentives are there, and, after all, universities are among the foremost practitioners of differential pricing, with high tuition coupled with high levels of financial aid. So why should they not be subjected to it as well? Until the late 1990s, pricing for scholarly journals was simple and uniform (at least for libraries, publishers were already moving into differential pricing by offering lower rates to individual subscribers as well as to less-developed countries). Now we have a 4.5 or greater differential between state universities in the U.S., and surely much higher across the world, where many countries do have concessionary deals.

This extensive and intensive application of price discrimination was accomplished surreptitiously. It is only because of the efforts of Ted Bergstrom and his colleagues [12] that we have a few details, and their efforts were impeded by publishers filing lawsuit to stop the disclosure. (In addition we have the indirect evidence given by the statistics of this paper.) One might think that Elsevier would be glad to demonstrate that, contrary to its reputation as a predatory profit-maximizer, it was engaging in the very socialist activity of leveling access to information by charging the rich more than the poor. But such is not the case. And it is easy to understand why, as issues of fairness arise even in dealing with 
large universities. It is easy for Harvard to appeal to its alumni to donate so that Harvard's libraries can be the best in the world, and provide an advantage for Harvard faculty and students. It is a trickier thing to ask Harvard alumni to donate to their alma mater just so it can pay ten times as much as some unknown school in the boondocks for the same degree of access to Elsevier journals.

Another noteworthy point about the spread of "Big Deals" is how slow it was. Why did the developments visible in Fig. 1 not occur a decade earlier? Part of the reason is surely that publishers have been slow to learn. They spent much of the late 1990s playing around with schemes to charge individuals for each access. These experiments, such as the PEAK one run by Elsevier, were costly and annoying to the scholars who got involved [46]. They should have been seen as doomed right from the beginning, but the industry had to learn this lesson for itself. And even after they realized that "Big Deals" was the best way to proceed, it took a while for it to be widely accepted. Librarians may not be as conservative in their ways as academics, but still the terms of the contracts had to be hammered out, the budgeting and contracting procedures changed, etc. Note that the sensitivity to price discrimination in dealing with academia is not as severe as in dealing with the public. In general, differential pricing is far more common in business to business transactions. This slow spread of price discrimination in academic publishing likely foreshadows its slow spread in consumer pricing as well.

One reason the differential pricing practices of the "Big Deals" could be implemented effectively was the gain in information by publishers about usage of their products. In the old print world, they knew very little about it. The librarians knew more, but even the librarians had limited knowledge, not much more than the frequency of circulation of print volumes. With the move to online distribution, much more precise measures became available, and now the publishers have the upper hand. While they do share some information with libraries, they can aggregate and compare data from different institutions, and of course they have information about library and entire university budgets. Thus this offers another example of how loss of privacy facilitates price discrimination.

Some other publisher practices are also what we find elsewhere. Prices are always presented as discounted from some notional list price, and never as surcharges imposed on rich institutions. From the standpoint of the standard economic model, it does not matter which method is used. But Homo sapiens is not Homo economicus, and how prices are presented matters a lot. That's why universities practice price discrimination by having high tuition and offering frequent and large discounts (called scholarships and the like). And that is why we are moving to a world in which Starbucks will likely raise the standard price of their Caramel Frappuccino to $\$ 9.95$, and never discount it below $\$ 8$ for somebody who is rich and a Caramel Frappuccino addict, while somebody who can't tell the difference between a Caramel Frappuccino from Starbucks and a regular cup of Macdonald's coffee will get discounts lowering the effective price to $\$ 2$. (The mobile world, where the nature of the discount can be obfuscated due to location and other circumstances, will likely facilitate such developments.)

The final major lesson from "'Big Deals" is that however hard the public may dislike price discrimination, it is hard to stop. Sellers will have strong incentives to employ 
it, especially as competition intensifies. With their resources, and incentives to cooperate, consumers are unlikely to be able to protect themselves. Further, even if they could, it is unlikely they will bother. Historical precedents suggest they will turn to the government to step in and regulate objectionable practices [58,64. However, governments have often played ambiguous roles, paying lip service to public demands, but facilitating price discrimination. Some differential pricing can be criticized for targeting the poor (or, more frequently, the ignorant, who are often, but not always, poor) 83. But very often it can be shown to have positive social effects. Such is the case with progressive taxation, with college tuition practices, and with prescription drug price differences between countries [45]. The murkiness of many of these deals does leave ground for criticism. (For example, one index shows drug prices in Mexico as $24 \%$ higher than in the U.S., which is high on the list, but not the highest.) But there is a "highly significant positive correlation between per capita income and the drug price index," so on balance it is easy to argue they are good for the world as a whole. The "Big Deal" practices also appear to have enhanced social welfare. One can argue that the world would have been better had libraries and researchers moved to squeeze out publishers and move Open Access forward faster. But both groups have been slow to act, while publishers are providing visibly better service through "Big Deals," as is seen in Fig. 1. Hence why should even well-intentioned regulators step in? Chances are that similar arguments will prevail in many other situations, and that in spite of public opposition, price discrimination will spread.

\section{Conclusions}

The most important developments in scholarly publishing are taking place quietly, with essentially no public discussion. The traditional roles of the two key intermediaries, libraries and publishers, are shrinking. New opportunities are opening up, however, which forces those two groups into new roles, and brings in new agents (such as Google). Who will perform what functions is open to competition, and at this point the publishers are doing better than libraries. Whether this will continue, and what the role of new agents that are competing for these functions will be is hard to predict. However, publishers have provided much better access to scholarly information through the often criticized "Big Deal" packages.

The evolution of the academic information market suggests that the general economy

will continue to evolve in ways contrary to common predictions. Opaque markets and price discrimination are likely to play an increasing role.

\section{Notes}

${ }^{1}$ As in all of this paper, only the large North American institutions that are represented in the ARL are considered. The cost structure is often different in other places, in particular in the less-developed world, where labor costs are lower.

${ }^{2}$ One of the few recent items that even touched on the subject was a post by Phil Davis [21] that cited the decreasing fraction of university budgets available for internal 
expenses as a sign of greater efficiency inside libraries. As is argued here, it is more a case of publishers performing more of the work that was traditionally in the domain of librarians than of librarians being more efficient.

${ }^{3}$ See Section 5 ,

${ }^{4}$ However, this observation should be treated with caution. Library budgets and purchasing patterns depend heavily on the nature of the institution, for example whether it has a medical school, or a law school, and so on. Therefore it would not necessarily be justified to conclude that the higher prices that "small" institutions paid per serial in 1990 compared to "large" ones represented price discrimination. However, the relative gains visible in Fig. 2 do appear to clearly favor "small" schools.

${ }^{5}$ There were various other factors that were disregarded, as they did not appear to lead to large changes in the relevant statistics. For example, starting with the 2007 report, ARL members were asked to report serial titles that were received, and not subscriptions.

${ }^{6} \mathrm{It}$ is worth pointing out, though, that the chart for the 17 members that reported since 1966 shows an initial jump from a level of about $2.9 \%$, and then essentially a constant fraction until about 1980, when the decline starts.

${ }^{7}$ The GDP growth rates are derived from 〈http://www.usgovernmentspending.com/us_gdp_history\#usgs101〉, the CPI ones from $\langle\mathrm{ftp}$ ://ftp.bls.gov/pub/special.requests/cpi/cpiai.txt $\rangle$. The other figures are from ARL compilations. Although ARL has many Canadian members, this presentation is U.S.-centric and ignores the fact that Canadian data is part of the ARL reports.

${ }^{8}$ See [84] or the Jan. 6, 2012, announcement of the Simba Information report, $\langle$ http://www.simbainformation.com/about/release.asp?id=2503〉. Many sources look only at STM publications, but one needs to consider also the humanities, etc., which, while not large in terms of revenues, are not negligible.

${ }^{9}$ Figures derived from the 2010-2011 Annual Report [3]. (A more accurate accounting would almost surely produce a somewhat lower figure, though, as the revenue figure includes services provided to other scholarly organizations.) That report shows total publications program revenues of $\$ 19.5$ million and expenses of $\$ 14.7$ million, for a profit margin of $25 \%$. This appears to be not atypical of nonprofit professional societies, which often use profits from publications to subsidize their other activities.

${ }^{10}$ As was clear two decades ago [56], and as has now been confirmed by various large-scale projects, such as that of the Internet Archive, one can digitize a book for about $\$ 20$ per copy on average. Hence the $\$ 884$ million spent on serials around 2010 , would have paid for conversion of over 40 million volumes, far more than the number of unique sets that are out of copyright. (Harvard reports about 17 million volumes total, the Library of Congress, 35 million, and this is for everything, including recent publications.)

${ }^{11}$ As another example of the cautious and incremental librarian approaches, consider the study [74] of costs of print and electronic journal subscriptions. It was far too conservative in the estimates of moving to "Big Deals," in which per-journal costs outside the purchase price are negligible. 


\section{Acknowledgments}

Thanks are due to Claudio Aspesi, Ted Bergstrom, Kris Fowler, Paul Ginsparg, Stevan Harnad, and Jonathan Smith for providing helpful information or comments.

\section{References}

1. R. Abelson and J. Creswell, "Few savings from digital health records," New York Times, Jan. 11, 2013.

2. S. Adams, The Dilbert Future: Thriving on Business Stupidity in the 21st Century, HarperCollins, 1998.

3. American Mathematical Society annual reports, available at 〈http://www.ams.org/about-us/annual-reports/annual-reports〉.

4. D. N. Arnold and H. Cohn, "Mathematicians take a stand," Notices Amer. Math. Soc., vol. 59, no. 6, June/July 2012, pp. 828-833. Available at 〈http://www.ams.org/notices/201206/rtx120600828p.pdf $\rangle$.

5. C. Aspesi and A. Sleeman, "Professional publishers: That long black cloud is coming down? The future of science, technical \& medical publishing," Bernstein Research report, July 16, 2009.

6. C. Aspesi and A. Sleeman, "Reed Elsevier: New ARL survey shows that academic library budgets are likely to deteriorate further next year," Bernstein Research report, April 19, 2011.

7. C. Aspesi, A. Rosso, and R. Wielechowski, "Occupy Elsevier," Bernstein Research report, February 6, 2012.

8. C. Aspesi, A. Rosso, and R. Wielechowski, "Reed Elsevier: A short history of two days in July (and why investors should care)," Bernstein Research report, September 10, 2012.

9. Association of Research Libraries (ARL), Statistics \& Assessment, $\langle$ hhttp://www.arl.org/stats/index.shtml .

10. Association of Research Libraries (ARL), "University \& library expenditures," 〈http://www.arl.org/stats/annualsurveys/eg/index.shtml $\rangle$.

11. T. Bergstrom, "Librarians and the terrible fix: Economics of the Big Deal," Serials: The Journal for the Serials Community, vol. 23, no. 2, July 2010, pp. 77-82. 〈http://uksg.metapress.com/content/64q7408826870771/fulltext.pdf $\rangle$.

12. T. Bergstrom, P. Courant, and R. P. McAfee, Big Deal Contract Project, $\langle$ http://www.econ.ucsb.edu/ tedb/Journals/BundleContracts.html $\rangle$.

13. B.-C. Björk, A. Roosr, and M. Lauri, "Global annual volume of peer reviewed scholarly articles and the share available via different open access option," in Proc. 12th International Conference on Electronic Publishing, L. Chan and S. Mornati, eds., 2008, pp. 178-186. Available at 〈http://elpub.scix.net/cgi-bin/works/Show?178_elpub2008〉.

14. S. Clifford, "Knowing cost, the customer sets the price," New York Times, March 28, 2012.

15. S. Clifford, "Shopper alert: Price may drop for you alone," New York Times, Aug. 10, 2012. 
16. S. Clifford, "Retail frenzy: Prices on the Web change hourly," New York Times, Dec. 1, 2012.

17. S. Clifford, "Keeping an eye on bouncing prices online," New York Times, Jan. 28, 2013.

18. P. Coburn, The Change Function: Why Some Technologies Take Off and Others Crash and Burn, Portfolio, 2006.

19. The Cost of Knowledge, web site of the 2012 Elsevier boycott movement, $\langle$ http://thecostofknowledge.com/ $\rangle$.

20. S. Craig, "What restaurants know (about you)," New York Times, Sept. 5, 2012.

21. P. Davis, "Libraries receiving a shrinking piece of the university pie," blog post, Feb. 15, 2012, 〈http://scholarlykitchen.sspnet.org/2012/02/15/a-shrinking-piece-of-theuniversity-pie/ $\rangle$.

22. C. Duhigg, "How companies learn your secrets," New York Times, Feb. 19, 2012. Available at 〈http://www.nytimes.com/2012/02/19/magazine/shopping-habits.html .

23. "Open sesame," editorial, Economist, April 14, 2012.

24. "Counter revolution: Fusty old retail banking faces its biggest shake-up in 200 years," Economist, May 19, 2012.

25. "Caveat emptor.com" (editorial) and "How deep are your pockets? Businesses are offered software that spots which customers will pay more," Economist, June 30, 2012.

26. B. D. Edgar and J. Willinsky, "A survey of scholarly journals using Open Journal Systems," Scholarly and Research Communication, vol. 1, no. 2, 2010. Available at $\langle$ http://journals.sfu.ca/src/index.php/src/article/view/24〉.

27. R. B. Ekelund, Jr., and R. F. Hébert, Secret Origins of Modern Microeconomics: Dupuit and the Engineers, Univ. Chicago Press, 1999.

28. Reed Elsevier, Annual Reports ands Financial Statements. 2011, available at $\langle$ http://reporting.reedelsevier.com/staticreports/Reed_AR_2011.pdf $\rangle$.

29. 21st European Conference on Information Systems. Track 22: Personal Data Markets, call for papers, 〈https://sites.google.com/site/ecis2013nl/the-conference/tracksand-keynotes/personal-data-markets $\rangle$.

30. A. Finder, "E-book borrowing, preceded by e-book waiting," New York Times, April 12, 2012.

31. P. C. Fishburn, A. M. Odlyzko, and R. C. Siders, "Fixed fee versus unit pricing for information goods: Competition, equilibria, and price wars," First Monday, vol. 2, no. 7, July 1997. Revised version in Internet Publishing and Beyond: The Economics of Digital Information and Intellectual Property, B. Kahin and H. R. Varian, eds., MIT Press, 2000, pp. 167-189. First Monday version at 〈http://firstmonday.org/htbin/cgiwrap/bin/ojs/index.php/fm/article/view/535/456〉.

32. B. Gates with N. Myhrvold and P. Rinearson, The Road Ahead, Viking, 1995.

33. B. Gates with C. Hemingway, Business @ the Speed of Thought: Using a Digital Nervous System, Warner, 1999.

34. S. Harnad, "The Green Road to Open Access: A leveraged transition," in The Culture of Periodicals from the Perspective of the Electronic Age, A. Gacs, ed., L'Harmatian, 2007, pp. 99-105. Available at 〈http://eprints.soton.ac.uk/263309〉. 
35. S. Harnad, "Open Access to research: Changing researcher behavior through university and funder mandates," JEDE M Journal of Democracy and Open Government, vol. 3, no. 1, 2011, pp. 33-41.

36. S. Harris, "Moving towards an open access future: The role of academic libraries," SAGE report, August 2012. Available at 〈http://www.uk.sagepub.com/repository/binaries/pdf/Library-OAReport.pdf .

37. C. Hoofnagle, J. Urban, and S. Li, "Mobile payments: Consumer benefits \& new privacy concerns," 2012 report, available at $\langle$ http://ssrn.com/abstract $=2045580\rangle$.

38. J. W. Houghton, "The costs and potential benefits of alternative scholarly publishing models," Information Research, vol. 16, no. 1, March 2011. Available at $\langle$ http://informationr.net/ir/16-1/paper469.html〉.

39. J. Houghton and A. Swan, "Planting the green seeds for a golden harvest: Comments and clarifications on "Going for Gold"," D-Lib Magazine, Jan./Feb. 2013, vol. 19, no. 1/2, 〈http://www.dlib.org/dlib/january13/houghton/01houghton.html .

40. D. W. King, "The cost of journal publishing: A literature review and commentary," Learned Publishing, vol. 20, no. 2, April 2007, pp. 85-106. Available at 〈http://www.ingentaconnect.com/content/alpsp/lp/2007/00000020/00000002/art0000〉.

41. S. Kolowich, "Smaller servings for libraries," Inside Higher Ed, Feb. 21, 2012, 〈http://www.insidehighered.com/news/2012/02/21/library-budgets-continue-shrinkrelative-university-spending $\rangle$.

42. B. Kuchera, "The dystopian future of casual games: Personalized, targeted pricing and mechanics," The Penny Arcade Report, Jan. 23, 2013, 〈http://pennyarcade.com/report/editorial-article/the-dystopian-future-of-casual-games-personalizedtargeted-pricing-and-mech $\rangle$.

43. F. Lalli, "A health insurance detective story," New York Times, Dec. 2, 2012.

44. T. Lewin, "Senate committee report on for-profit colleges condemns costs and practices," New York Times, July 30, 2012.

45. F. R. Lichtenberg, "Pharmaceutical price discrimination and social welfare," Capitalism and Society, vol. 5, issue 1, 2010, article 2.

46. W. Lougee and J. MacKie-Mason, eds., Economics and Usage of Digital Libraries: Byting the Bullet, University of Michigan University Library, 2008. $\langle$ http://quod.lib.umich.edu/cgi/t/text/text-idx?c=spobooks;;idno=5621225.0001.001〉.

47. M. A. Mabe, "Scholarly communication: A long view," New Review of Academic Librarianship, vol 16, supplement 1 (special issue on Dissemination Models in Scholarly Communication), 2010, pp. 132-144. Available at 〈http://www.tandfonline.com/doi/abs/10.1080/13614533.2010.512242〉.

48. D. Mattioli, "On Orbitz, Mac users steered to pricier hotels," Wall Street Journal, June 6, 2012.

49. E. E. Maxwell, The Future of Taxpayer-Funded Research: Who Will Control Access to the Results?, Committee for Economic Development, 2012. Available at 〈http://www.ced.org/images/content/issues/innovationtechnology/DCCReport_Final_2_9-12.pdf $\rangle$. 
50. M. J. McCabe, C. M. Snyder, and A. Fagin, "Open Access versus traditional journal pricing: Using a simple 'platform market' model to understand which will win (and which should)." Available at $\langle$ http://ssrn.com/abstract $=2201773\rangle$.

51. J. Mikians, L. Gyarmati, V. Erramilli, and N. Laotaris, "Detecting price and search discrimination on the Internet," HotNets 2012 workshop. Available at 〈http://conferences.sigcomm.org/hotnets/2012/papers/hotnets12-final94.pdf〉.

52. C. Moffett, N. Del Deo, and A. Chan, "Quick take - AT\&T (T): Market share(ing) Part II ... A quieter voice," BernsteinResearch report, July 18, 2012.

53. H. Morrison, Scholarly Communication for Librarians, Chandos, 2009.

54. H. Morrison, The Economics of Scholarly Communication in Transition, Ph.D. thesis draft of Jan. 21, 2012, 〈http://pages.cmns.sfu.ca/heathermorrison/files/2012/01/Heather-Morrison-thesis-draft-Jan-21-2012.pdf $\rangle$.

55. E. Noam, "Electronics and the dim future of the university," Science, vol. 270, Oct. 13, 1995, pp. 247-49.

56. A. Odlyzko, "Tragic loss or good riddance? The impending demise of traditional scholarly journals," Intern. J. Human-Computer Studies, 42 (1995), pp. 71-122, and J. Univ. Comp. Sci., pilot issue, vol. 0, 1994. Available at 〈http://www.dtc.umn.edu/ odlyzko/doc/tragic.loss.long.pdf .

57. A. Odlyzko, "The decline of unfettered research," 1995 manuscript, available at $\langle$ http://www.dtc.umn.edu/ odlyzko/doc/decline.pdf $\rangle$.

58. A. Odlyzko, "The bumpy road of electronic commerce," WebNet 96 - World Conf. Web Soc. Proc., H. Maurer, ed., AACE, 1996, pp. 443-456. Available at $\langle$ http://www.dtc.umn.edu/ odlyzko/doc/bumpy.road.pdf $\rangle$.

59. A. Odlyzko, "The economics of electronic journals," First Monday, vol. 2, no. 8, August 1997. Revised version in Technology and Scholarly Communication, R. Ekman and R. E. Quandt, eds., Univ. Calif. Press, 1999, pp. 380-393. First Monday version at 〈http://firstmonday.org/htbin/cgiwrap/bin/ojs/index.php/fm/article/view/542/463〉.

60. A. Odlyzko, "The slow evolution of electronic publishing," Electronic Publishing '97: New Models and Opportunities, A. J. Meadows and F. Rowland, eds., ICCC Press, 1997, pp. 4-18. Available at 〈http://www.dtc.umn.edu/ odlyzko/doc/slow.evolution.pdf $\rangle$.

61. A. Odlyzko, "Electronics and the future of education," On the Horizon, vol. 5, no. 4, July/August 1997, pp. 8-9. Extended version available at $\langle$ http://www.dtc.umn.edu/ odlyzko/doc/electronics.education.txt $\rangle$.

62. A. Odlyzko, "Competition and cooperation: Libraries and publishers in the transition to electronic scholarly journals," Journal of Electronic Publishing, vol. 4, no. 4, May 1999, 〈http://quod.lib.umich.edu/cgi/t/text/textidx? $\mathrm{c}=$ jep; view $=$ text;rgn $=$ main;idno $=3336451.0004 .411\rangle$.

63. A. Odlyzko, "The rapid evolution of scholarly communication," Learned Publishing, vol. 15, no. 1, Jan. 2002, pp. 7-19. Revised version in Economics and Usage of Digital Libraries: Byting the Bullet, W. Lougee and J. MacKieMason, eds., University of Michigan University Library, 2008. Available at $\langle$ http://quod.lib.umich.edu/s/spobooks/5621225.0001.001/1:4.2?rgn=div2;view=fulltext .

64. A. Odlyzko, "Privacy, economics, and price discrimination on the Internet," ICEC2003: Fifth International Conference on Electronic 
Commerce, N. Sadeh, ed., ACM, 2003, pp. 355-366. Available at $\langle$ http://www.dtc.umn.edu/ odlyzko/doc/privacy.economics.pdf $\rangle$.

65. A. Odlyzko, "The volume and value of information," International Journal of Communication, vol. 6, 2012. Online journal version: 〈http://ijoc.org/ojs/index.php/ijoc/article/view/1570/740〉.

66. F. Partnoy and J. Eisinger, "What's inside America's banks?," Atlantic, January/February 2013. Available at 〈http://www.theatlantic.com/magazine/archive/2013/01/whats-inside-americasbanks $/ 309196 /\rangle$.

67. PolyMath Journal publishing reform web page, 〈http://michaelnielsen.org/polymath1/index.php?title=Journal_publishing_reform $\rangle$.

68. R. Pogrebin and K. Flynn, "As art values rise, so do concerns about market's oversight," New York Times, Jan. 28, 2013.

69. S. Pulliam and B. Barry, "Executives' good luck in trading own stock," Wall Street Journal, Nov. 28, 2012.

70. S. Pulliam, R. Smith, and M. Siconolfi, "U.S. investors face an age of murky pricing; Values of securities tougher to pin down," Wall Street Journal, Oct. 12, 2007.

71. R. C. Rabin, "Report faults high fees for out-of-network care," New York Times, Feb. 1, 2013.

72. Reed Elsevier, Annual Reports and Financial Statements 2011, available at 〈http://reporting.reedelsevier.com/staticreports/Reed_AR_2011.pdf .

73. P. H. Rubin and T. M. Lenard, Privacy and the Commercial Use of Personal Information, Kluwer, 2002.

74. R. C. Schonfeld, D. W. King, A. Okerson, and E. G. Fenton, "The nonsubscription side of periodicals: Changes in library operations and cost between print and electronic formats," Council on Library and Information Resources, 2004. Available at $\langle$ http://www.clir.org/PUBS/reports/pub127/pub127.pdf $\rangle$.

75. N. Singer, "Your online attention, bought in an instant," New York Times, Nov. 18, 2012.

76. N. Singer, "Data protection laws, an ocean apart," New York Times, Feb. 3, 2013.

77. M. D. Smith, "Fake reviews plague consumer websites," Guardian, Jan. 26, 2013.

78. D. J. Solomon and B.-C. Björk, "A study of open access journals using article processing charges," J. American Society for Information Science and Technology, to appear. Available at $\langle$ http://www.openaccesspublishing.org/apc2/preprint.pdf $\rangle$.

79. D. J. Solove, "Privacy and power: Computer databases and metaphors for information privacy," Stanford Law Rev., vol. 53, no. 6, July 2001, pp. 1393-1462.

80. D. Streitfeld, "As boom lures app creators, tough part is making a living," New York Times, Nov. 18, 2012.

81. A. Swan and J. Houghton, Going for Gold? The costs and benefits of Gold Open Access for UK research institutions: Further economic modeling, report to the UK Open Access Implementation Group, June 2012. Available at 〈http://ie-repository.jisc.ac.uk/610/2/Modelling_Gold_Open_Access_for_institutions__final_draft3.pdf $\rangle$. 
82. J. Valentino-DeVries and J. Singer-Vine, "You're looking at the premium package, right?' Companies today are increasingly tying people's real-life identities to their online browsing habits," Wall Street Journal, Dec. 8, 2012.

83. J. Valentino-DeVries, J. Singer-Vine, and A. Soltani, "Websites vary prices, deals based on users' information," Wall Street Journal, Dec. 24, 2012.

84. M. Ware and M. Mabe, The STM Report: An Overview of Scientific and Scholarly Journals Publishing, International Association of Scientific, Technical and Medical Publishers, 2009. Available at 〈http://www.stmassoc.org/2009_10_13_MWC_STM_Report.pdf). 